\title{
An Aerodynamic Data System for Small Hovering Fixed-Wing UAS
}

\author{
Derrick Yeo, ${ }^{*}$ Joshua Henderson ${ }^{\dagger}$ Ella Atkins ${ }^{\sharp}$ \\ University of Michigan, Ann Arbor
}

Small fixed-wing UAS that are able to hover combine the station keeping abilities of a rotary wing platform and the extended range of conventional aircraft. Current autopilots for these vehicles rely on inertial measurements plus airspeed to transition from forward flight to hover, accumulating appreciable position error during the transition. Once in hover, a combination of inertial and GPS data is used for station keeping. By combining additional real-time aerodynamic data with traditional inertial measurements, the aircraft can maintain high angle-of-attack operation for controlled slow flight and execute forward/vertical flight transitions closer to stall. Such a capability can expand the autonomous maneuver repertoire as well as improve accuracy at which existing maneuvers are conducted. This paper describes the design, implementation, and testing of a small-scale aerodynamic data system augmenting a traditional inertial navigation system. Collected aerodynamic data includes angle of attack, sideslip angle, airspeed, and pressure distribution along the wing chord. Wind tunnel tests verify the calibrated air-data probe can measure angles of attack from $-75^{\circ}$ to $75^{\circ}$ and sideslip angles from $-45^{\circ}$ to $45^{\circ}$. The aerodynamic-inertial data system was incorporated into a Funtana hobbyist airframe with thrust exceeding weight. Flight test results from a series of forward-hover transitions are presented, along with requisite guidance and flight control laws for autonomous operation.

$\begin{array}{ll}\mathrm{C}_{\mathrm{p}} & =\text { Coeficent of Pressure } \\ \beta & =\text { Sideslip Angle } \\ \mathrm{V}_{\text {air }} & =\text { Air Speed } \\ \mathrm{c}_{i} & =\text { Cubic Coefficent of Curve Fits } \\ \mathrm{m}_{\mathrm{i}} & =\text { Linear Slope of Curve Fits } \\ \mathrm{P}_{\mathrm{i}} & =\text { Wing Pressure Port Measurement }\end{array}$

Nomenclature
\[ \begin{array}{cl}\propto & =\text { Angle of Attack } \\ \mathrm{c} & =\text { Wing Chord } \\ \mathrm{q} & =\text { Dynamic Pressure } \\ \mathrm{a}_{i} & =\text { Quadratic Coefficent of Curve Fits } \\ \mathrm{b}_{\mathrm{i}} & =\mathrm{Y}-\text { Intercept of Curve Fits }\end{array} \]

\section{Introduction}

$\mathrm{S}_{\mathrm{s}}^{\mathrm{N}}$ MALL unmanned air systems (UAS) with the ability to efficiently transition from steady level flight to a stationary hover have applications across military and commercial sectors. Such a platform can provide stationary close-range reconnaissance but still move quickly and efficiently to a new location. Lightweight fixedwing hobbyist airframes can provide sufficient thrust to hover as well as fly conventionally. Previous research efforts $^{1,2}$ have in fact demonstrated autonomous control of transitions between conventional and hovering flight. Frank et $\mathrm{al}^{1}$ rely on an indoor Vicon positioning system for feedback of precise position, velocity, and attitude information to the controller, while Johnson et $\mathrm{al}^{2}$ rely on inertial sensors plus airspeed for outdoor autonomous flight, experiencing large-magnitude altitude excursions particularly during transition. Controllers such as that proposed by Johnson et $\mathrm{al}^{2}$ rely on locally-linearized control laws for steady-level and hovering flight modes. A linear ramp-up/ramp-down on pitch and airspeed is commanded to transition between forward-flight and hover modes. Though this method can successfully make transitions to/from hover, the transition itself is open-loop over the aerodynamics, resulting in appreciable transients not straightforward to eliminate with existing feedback.

We propose a vehicle control system that relies strictly on embedded sensors to successfully operate in steady-state conventionally, at hover, and in "slow-flight" high-angle-of-attack and/or high-sideslip configurations as desired. We further seek to minimize errors accumulated during transition between these flight modes. To accomplish these goals, we propose as a first step incorporating a sensor suite capable of better capturing the fundamental aerodynamic lift and drag forces applied to the airframe as well as better measuring aircraft motion relative to the surrounding air. At unusual attitudes or very slow airspeeds, conventional Pitot tube systems fail to provide useful

\footnotetext{
* Graduate Student Research Assistant, Aerospace Engineering Dept., University of Michigan.

† Undergraduate Student Researcher, Aerospace Engineering Dept., University of Michigan.

$\$$ Associate Professor, Aerospace Engineering Dept., University of Michigan, Associate Fellow.
} 
airflow data. We propose instead an embedded aerodynamic data system that measures not only undisturbed air flow in multiple directions but also flow along a representative wing chord cross-section. Our hypothesis is that, with this additional data, we can better control motion through robust wind vector speed and direction as state feedback and through better knowledge of aerodynamic force application with respect to separation (stall) conditions. Long-term, achievement of high-precision unusual attitude equilibrium (trim) states and transitions between these states will enable even low-cost fixed-wing UAS to accurately maneuver under bridges or through urban canyons at a much broader range of speeds and pointing directions than has previously been possible.

This paper focuses on the design, implementation, and flight testing of an aerodynamic data system embedded in a lightweight hobbyist airframe. We are continuing research to incorporate this data in an onboard controller, inspired by existing conventional ${ }^{3}$ and high-angle-of-attack ${ }^{4}$ autopilot systems. Below, the embedded aerodynamic data system is described, along with COTS inertial navigation system (INS), onboard PC/104-based flight computer, and data acquisition software. Aerodynamic measurements include airspeed, angle of attack, sideslip angle, and pressure distribution at four stations along the wind chord. The INS measures aircraft pitch, yaw, roll and their corresponding rates of change, as well as GPS-based inertial position and velocity. This aerodynamic-inertial data system has been embedded in a Funtana aerobatic airframe and flight tested over a series of radio-controlled and stability-augmented flight operations. Results evaluating the accuracy of the aerodynamic-inertial data system over a spectrum of conventional, high-angle-of-attack, [approximate] hover, and transition flight conditions are presented. The paper concludes with a presentation of guidance and control laws that exploit aerodynamic data to accurately track reference commands and transition between control modes.

\section{Aerodynamic Data System}

Our aerodynamic data package was configured to provide relative wind vector measurements as well as estimates of air flow over the wing. The system was designed to support relative wind vector measurements over a wide range of flight states and weather conditions. Consider a basic point-mass model for aircraft lift ${ }^{5}$ :

$$
L=\frac{1}{2} \rho V_{\text {air }}^{2} S c_{L}(\alpha)
$$

Typical UAS controllers ${ }^{3,4}$ effect an altitude change by commanding a change in pitch angle $\theta$. The underlying assumptions in such a model are that the difference between inertial pitch angle $\theta$ and angle of attack $\alpha$ is negligible, and that the aircraft coefficient of lift $c_{L}$ remains constant when in fact it is a function of $\alpha$. These approximations are appropriate under near-level flight conditions for which small angle approximations are acceptable and inaccuracies in lift estimates can be countered with feedback. At slow speeds and high angles of attack, however, the differences between angle of attack and pitch angle can be large depending on prevailing wind conditions. Also, aircraft $c_{L}$ is not constant and may not even be a linear function of alpha, particularly near the onset of stall. The aerodynamic data system provides measurements of the relative wind vector using a composite set of pitot probes as described below. Wing air flow is measured by a single set of wing pressure ports over the top of a specific wing chord section sufficiently distant from the wing root to minimize propeller or fuselage-induced disturbances.

\section{A. Angle of Attack, Sideslip Angle, and Pitot Probe Design}

An $\alpha-\beta$ probe was designed to be easily manufactured and to provide wind magnitude and direction measurements. Four thin aluminum tube probes were each aligned and attached to a standard pitot probe, as illustrated in Figure 1. The branch-like geometry allowed ports to be located far from the centerline of the probe. This avoided problems associated with measuring flow that was disturbed significantly by the probe itself, as described by Tropea ${ }^{7}$. The probe was calibrated in the University of Michigan's 2'x2' wind tunnel. A calibration was developed to accommodate a large range of flow angles, allowing angles of attack up to 75 degrees to be effectively measured. The calibration technique is similar to that described by Ostowari et $\mathrm{al}^{6}$ in which a change in reference port is effected to correctly characterize wind at high flow angles. At a moderate range of flow angles, the differential pressures measured by the $\alpha$ and $\beta$ tubes are normalized by the dynamic pressure measured by the Pitot probe to make the measurements independent of airspeed. Past 45 degrees, the inverse relationship is utilized because at high flow angles, the differential pressures measured by the $\alpha$ and $\beta$ tubes better represent the dynamic pressure. Combining both sets of calibrations give rise to separate calibration curves within their respective ranges, as described in the below wind tunnel results section. As will be shown, this system reliably measures airspeeds higher 
than $2.5 \mathrm{~m} / \mathrm{s}$ and angles of attack (and sideslip) up to 75 degrees. While commercial solutions are available, they are not catered to our specific project requirements for a low cost, quickly manufactured instrument that does not need the high level of precision that commercial systems offer at significantly higher cost.

\section{B. Wing pressure ports}

Aerodynamic lift and drag forces are characterized primarily by understanding the variable distribution of pressure across the top surface of the wing under variable flight conditions. Our system is currently capable of measuring a single chord-wise pressure variation or single $\mathrm{Cp}$-line over the top of a single chord station along the wing span. Pressure measurements of this type are similar to those taken in a traditional wind tunnel test of a given airfoil under 'infinite wing' parameters.

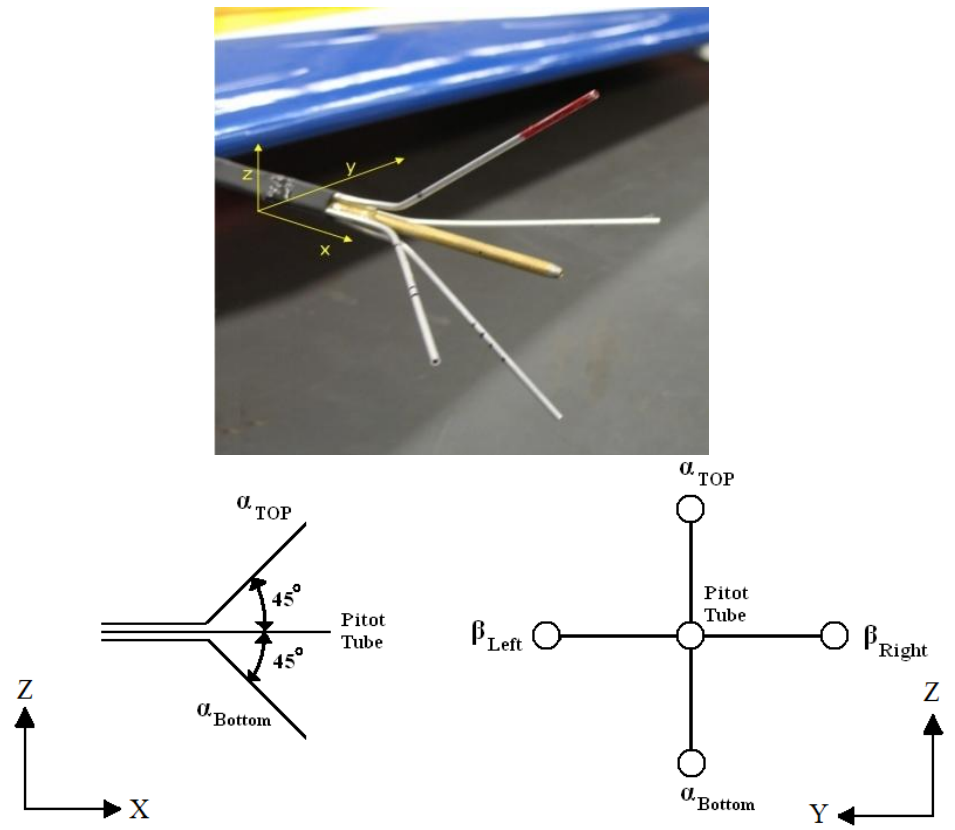

Figure 1: $\alpha-\beta$ Probe (Top: Wing-mounted Installation, Bottom: Design Schematic)

As a prediction of flight test results, XFOIL was used to generate a pressure plot (Figure 2) for a generic two dimensional airfoil using basic a vortex panel method. The simpler algorithm used in XFOIL was chosen to create the initial reference cases along with wind tunnel data taken at a Reynolds number comparable to the aircrafts estimated transition airspeed. Presuming a station away from wing root or tail (where the infinite length approximation holds), chordwise $\mathrm{Cp}$ lines can be used to estimate total wing lift using an analysis analogous to a Prandtl lift line analysis.
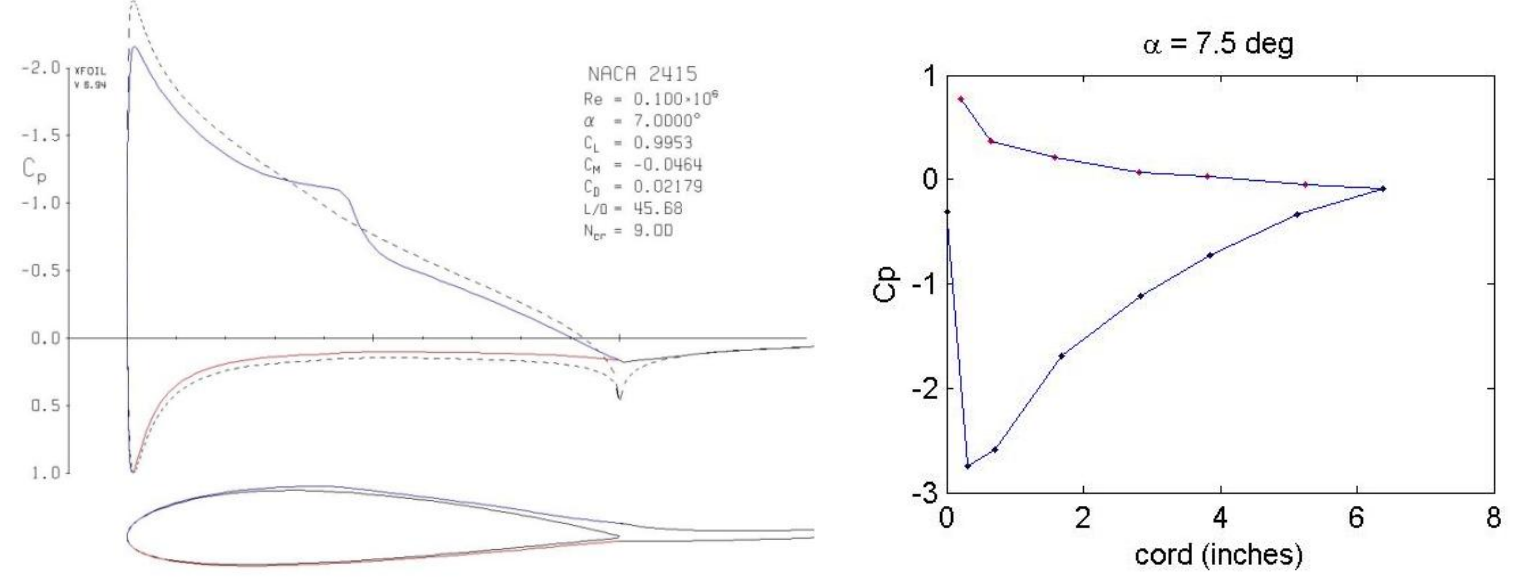

Figure 2: Expected infinite-span Cp-line from XFOIL and wind tunnel data (note that $\mathrm{Y}$ axis is reversed on XFOIL plot) 
Chordwise pressure port locations were chosen to allow adequate estimation of the Figure 2 curve with a limited number of sensors, and based on practical concerns such as not locating pressure ports inside an aileron. The ports were built from thin aluminum pipe stock which can be embedded in the internal wing structure of most typical R/C airframes. One port is located at the leading edge of the aircraft and captures the stagnation pressure of the airfoil. Measurements from the other ports are located along the chord and are referenced to stagnation pressure. Our pressure port system installed in a Funtana airframe is illustrated below in Figure 3. Currently four sensors generate an approximate measurement of the $\mathrm{Cp}$-line and allow for a stall detection scheme to be implemented. The pressure sensors used for our aerodynamic data system have a measurement range of 2 inches of water and are manufactured commercially. The sensors used on the wing ports have a measurement range of 5 inches of water to accommodate larger pressure differences. They are internally amplified and provide a ratio-metric output that is temperature compensated and pre-calibrated. Sensitivity ranges were chosen for the best measurement resolution based on expected pressures to be encountered.

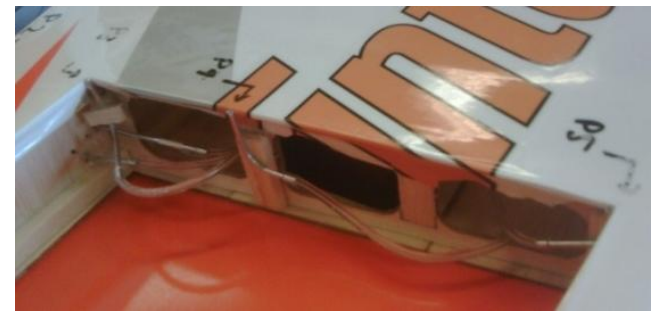

Figure 3: Wing Pressure Port Construction

\section{Inertial Navigation and Flight Computer Systems}

The Midg-II inertial navigation system, built by Microbotics Inc., was installed to provide filtered measurements of aircraft inertial state, including GPS-based position and velocity, attitude, and body axis angular velocities. The Midg-II measures these values using GPS, a 3-axis magnetometer, 3-axis rate gyro, and a 3-axis accelerometer. For this project, only attitude and angular rates are used to evaluate our aerodynamic data system. The Midg-II provides state and position measurement updates at a rate of $50 \mathrm{~Hz}$ communicated to our flight computer via RS-232 serial port connection. A servo switch controller (SSC) built by Microbotics Inc., was used to record the servo commands sent by the pilot to the servos during flight. The SSC also provides the capability for the flight computer to command servo positions when in an Autopilot mode and a safety switch for the pilot to recover the aircraft if the aircraft is in danger of crashing. The Diamond Systems Athena II was selected as the onboard computer. The Athena II includes multiple serial ports, an Ethernet port, flash disk, and a data acquisition package. The data acquisition system includes a16-bit analog to digital converter that can be sampled at a maximum rate of $200 \mathrm{kHz}$ given no other software instructions. The avionics package can be powered for approximately twenty-five minutes. Figure 4 shows the overall system block diagram.

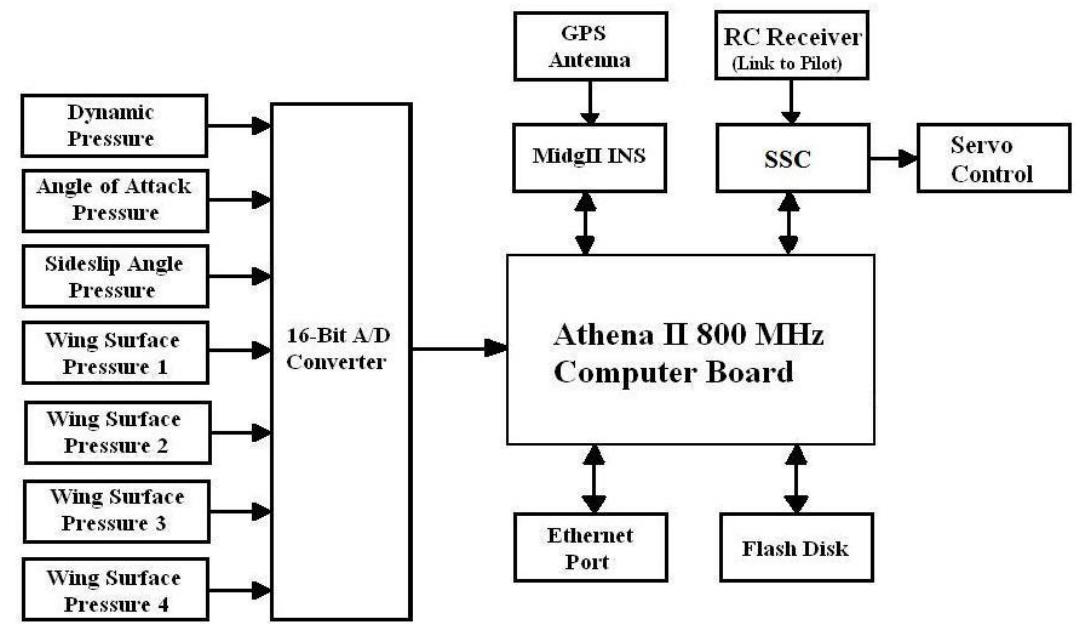

Figure 4: System Block Diagram 


\section{Aircraft Test Platform}

The Hangar-9 Funtana X100 is the COTS radio-controlled airplane chosen for our flight tests, shown in Figure 5. In addition to being fully aerobatic, it also supports appreciable avionics payload while maintaining sufficient thrust to stably hover (a thrust to weight ratio larger than 1.5 when fully loaded with an avionics payload of $1.4 \mathrm{~kg}$ ). The Funtana was also selected because of the large open volume inside the fuselage for installing and securing avionics components safely inside the aircraft structure. An electric motor propulsion system was chosen to minimize vibrations and eliminate the possibility of exhaust with entrained fuel, which could affect the airflow measurements. The motor was an E-flite Power 110 powered by two 4,150 mAH $14.8 \mathrm{~V}$ lithium ion batteries. Digital servos were used for all control surfaces. The ailerons used Hitech HS-5625MG servos, and the rudder and elevator used JR DS821 servos.

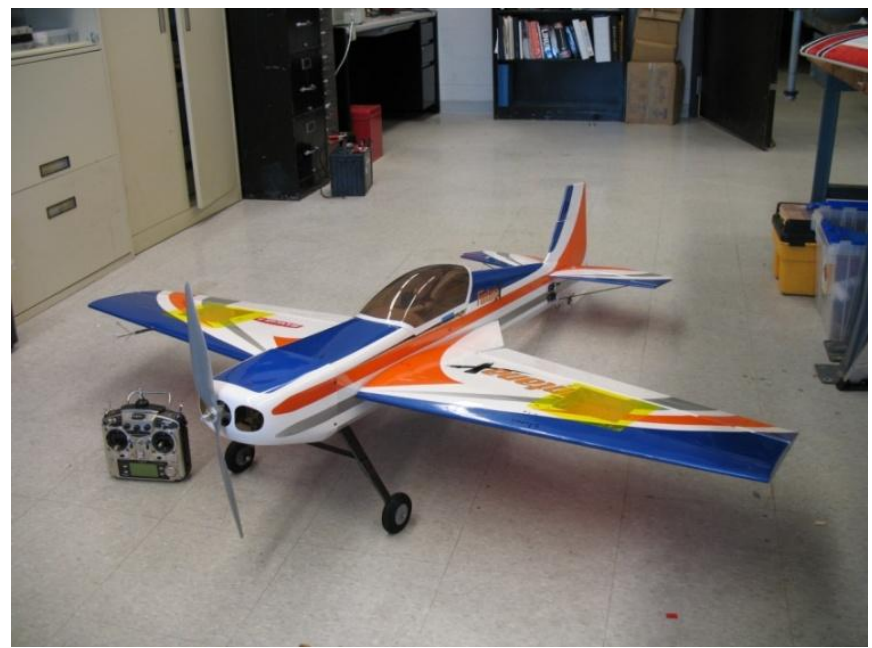

Figure 5: Funtana Test Aircraft (air data probe on right wing, chordwise pressure ports on left wing)

Table 1: Funtana Properties

\begin{tabular}{|c|c|}
\hline Wing Span $(\mathrm{cm})$ & 176.5 \\
\hline Wing Surface Area $\left(\mathrm{cm}^{2}\right)$ & 7,150 \\
\hline Weight with Payload $(\mathrm{kg})$ & 5.25 \\
\hline Payload Weight $(\mathrm{kg})$ & 1.40 \\
\hline
\end{tabular}

Preliminary flight testing showed that the chosen platform configuration retained its aerobatic capability while providing an approximate flight time of fifteen minutes. Table 1 lists airframe specifications for the Funtana. The pressure ports were arranged along the chord as follows: P1 (Stagnation) at 0\%, P2 at 13.3\%, P3 at 36.6\%, and P4 at $66.6 \%$. The chosen pressure transducers saturate at a maximum airspeed of about $22 \mathrm{~m} / \mathrm{sec}$ when used on the $\alpha-\beta$ probe. This limit easily meets the needs of the low speed mission profile of the Funtana. Two of the wing port sensors are 5inchH20 sensors to accommodate measuring the large pressure peak over the top of the wing. The $\alpha-\beta$ probe and wing pressure ports are connected with flexible Tygon tubing to individually wired pressure sensors mounted on a central circuit board.

\section{Calibration Algorithm and Stall Detection Technique}

\section{A. Calibration of the $\alpha-\beta$ Probe}

The calibration of the angle of attack, sideslip angle, and pitot $(\alpha-\beta)$ probe was performed in the University of Michigan's subsonic $2 \mathrm{ft} \times 2 \mathrm{ft}$ instructional wind tunnel. The first values measured in the wind tunnel were the nominal value of the pressure sensors at a velocity of zero, angle of attack of zero, and sideslip angle of zero. For seven different velocities, the angle of attack and sideslip angle were changed independently. Calibration velocities were $3,5.8,9,11,14,18$, and $22 \mathrm{~m} / \mathrm{sec}$. The angle of attack was varied from $-100^{\circ}$ to $100^{\circ}$ in $5^{\circ}$ increments except for the interval $\left[-10^{\circ}-2.5^{\circ}\right]$ measured in increments of $2.5^{\circ},\left[\begin{array}{ll}-1^{\circ} & 1^{\circ}\end{array}\right]$ in $1^{\circ}$ increments, and $\left[2.5^{\circ} 10^{\circ}\right]$ in $2.5^{\circ}$ increments. The sideslip angle was varied from $-45^{\circ}$ to $45^{\circ}$ in $5^{\circ}$ increments except for intervals $\left[-10^{\circ}-2.5^{\circ}\right]$ in increments of $2.5^{\circ},\left[-11^{\circ}\right]$ in $1^{\circ}$ increments, and $\left[2.5^{\circ} 10^{\circ}\right]$ in $2.5^{\circ}$ increments. The angle of attack and sideslip 
angles were varied over these ranges or until the sensors saturated. For the highest velocity of $22 \mathrm{~m} / \mathrm{s}$ the angle of attack was varied from $-20^{\circ}$ to $25^{\circ}$ and the sideslip angle was varied from $-15^{\circ}$ to $15^{\circ}$. Saturation of the sensors did not occur anywhere in the test range until the flow reached velocities of $18 \mathrm{~m} / \mathrm{s}$. Therefore the calibration is valid for the region in which we operate, which is the moderate velocity, high angle of attack region. For each measurement after the flow angle was changed, once the flow reached a steady state, ten seconds of data were taken. This data was then used to construct various calibrations curves to effectively measure angles of attack from $-75^{\circ}$ to $75^{\circ}$ and sideslip angles between $-45^{\circ}$ and $45^{\circ}$.

\section{B. Airspeed Calibration}

Airspeed was calibrated by using the measurement of the dynamic pressure for each airspeed at an angle of attack of $0^{\circ}$ and sideslip angle of $0^{\circ}$. This data yields the expected quadratic equation found in Figure 7 and shown in Eq. 2; note that dynamic pressure $q=\frac{1}{2} \rho V_{\text {air }}^{2}$. The data fits this curve well with some deviation as expected when pitot tubes measure very low speeds.

$$
V_{i}=a_{q}(q)^{2}+m_{q}(q)+b_{q}
$$

\section{A. Normalization by Pitot Probe Dynamic Pressure}

The angle of attack and sideslip angles are calculated using the pressure difference between the two tubes corresponding to either the angle of attack or sideslip angle and then are normalized by the dynamic pressure as measured by the Pitot tube. These ratios, as shown in Eq. 3, can then be related to the angle of attack and sideslip angle using linear curve fits shown in Eq. 4 and Eq. 5. These are the ratios of the current voltage reading subtracted by the sensor's nominal voltage at a flow velocity of zero.

$$
\begin{array}{lr}
\frac{\Delta \alpha}{\Delta q}=\frac{\alpha_{\mathrm{i}}-\alpha_{0}}{\mathrm{q}_{\mathrm{i}}-\mathrm{q}_{0}} \quad \frac{\Delta \beta}{\Delta \mathrm{q}}=\frac{\beta_{\mathrm{i}}-\beta_{0}}{\mathrm{q}_{\mathrm{i}}-\mathrm{q}_{0}} & \\
\alpha_{i}=\mathrm{m}_{\alpha 1} \frac{\Delta \alpha}{\Delta \mathrm{q}}+\mathrm{b}_{\alpha 1} & \text { For }-25^{\circ}<\alpha<25^{\circ} \\
\beta_{\mathrm{i}}=\mathrm{m}_{\beta 1} \frac{\Delta \beta}{\Delta \mathrm{q}}+\mathrm{b}_{\beta 1} & \text { For }-25^{\circ}<\beta<25^{\circ}
\end{array}
$$

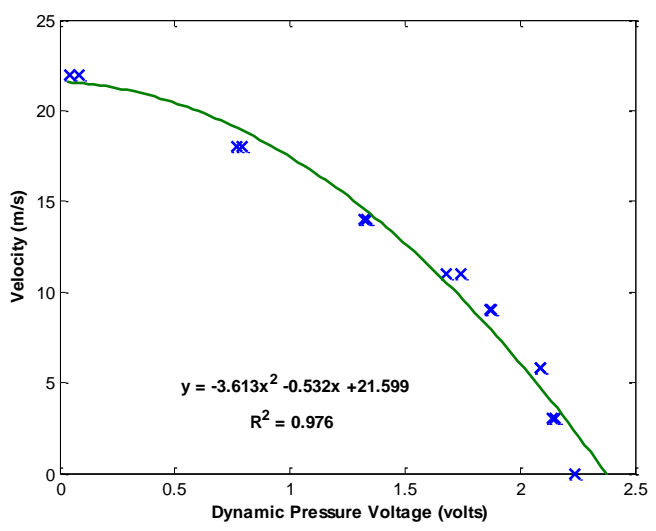

Figure 6: Airspeed Calibration Curve

Figures 8 and 9 show plots of these ratios as the angle of attack and sideslip angle are changed for various velocities. For both graphs there is a large range where the relationship between the ratios and angle of attack or sideslip angle is linear. There are also regions where the angle of attack is no longer independent of velocity. For angle of attack, the plot is linear for angles of attack between $-25^{\circ}$ and $25^{\circ}$. For angles of attack with a magnitude higher than $30^{\circ}$, the various curves are no longer independent of velocity as shown in an enlarged version of Fig.7 in Fig. 9 for angles of attack between $30^{\circ}$ and $100^{\circ}$. These errant regions are caused by cancellation errors occurring as the dynamic pressure approaches zero as this causes $\frac{\Delta \alpha}{\Delta q}$ to go towards infinity. This occurs when the pressure at the stagnation 
and static ports of the Pitot tube become the same, which occurs for angles near $45^{\circ}$ as the Pitot tube can no longer accurately measure the dynamic pressure. In Figure 8, the sideslip angle is linear for angles between $-25^{\circ}$ and $25^{\circ}$ and outside of this range the sideslip angle becomes nonlinear and by $30^{\circ}$ it can no longer be normalized by velocity as the curves diverge from each other similar to the angle of attack.

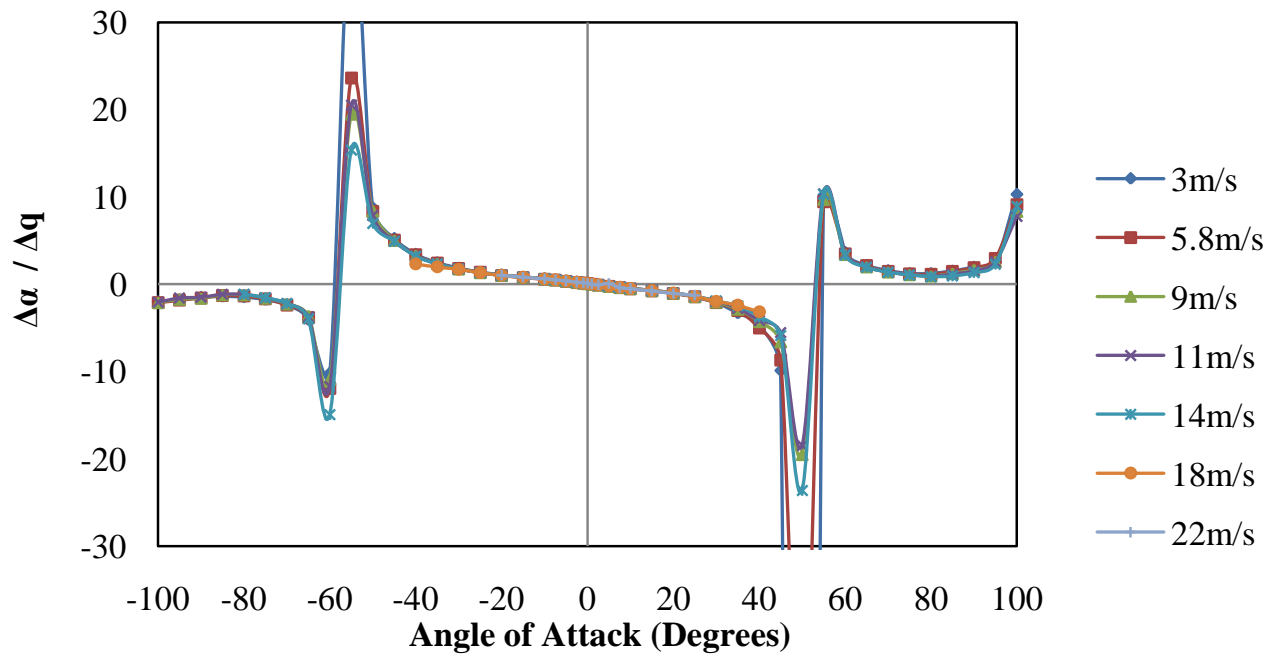

Figure 7: $\Delta \alpha / \Delta \mathrm{q}$ Differential Pressure Voltage Ratio vs. Angle of Attack

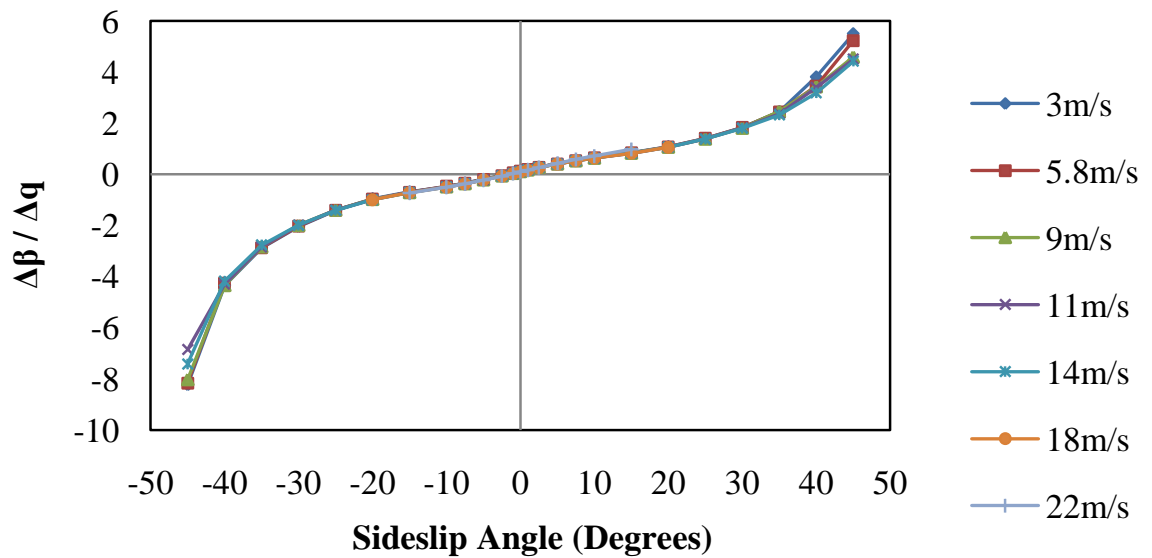

Figure 8: Sideslip Angle Calibration Curve Normalized By Dynamic Pressure

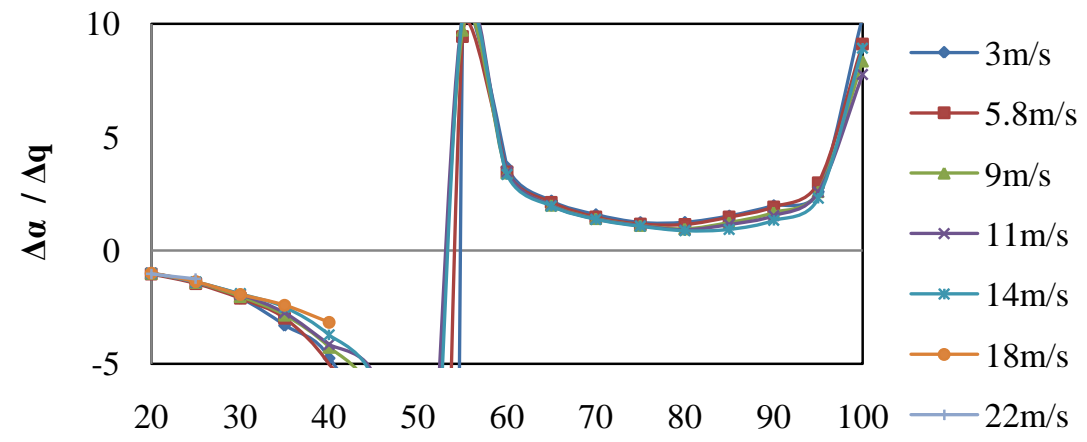

Angle of Attack (Degrees)

Figure 9: Normalization Failure of $\Delta \alpha / \Delta q$ 


\section{Normalization by New Reference Dynamic Pressure}

The previous method, normalization of the measured differential pressures by the dynamic pressure measured by the Pitot probe causes cancellation errors to occur when the airspeed approaches zero or when the angle of incidence is near $45^{\circ}$. By changing the reference dynamic pressure to be the pressure measured by the angle of attack tubes the cancellation errors are then moved to when the angle of attack or sideslip angle approach zero. ${ }^{6}$ The equations for these new ratios are shown below as Eq. 6. For the angle of attack, this method yields two cubic equations as shown in Eq. 7 and Eq. 8 because of the extended flow angles need for our goal of hovering flight. For the sideslip angle, this method yields two quadratic equations Eq. 9 and Eq. 10.

$$
\begin{array}{ll}
\frac{\Delta \mathrm{q}}{\Delta \alpha}=\frac{\mathrm{q}_{\mathrm{i}}-\mathrm{q}_{0}}{\alpha_{\mathrm{i}}-\alpha_{0}} \quad \frac{\Delta \mathrm{q}}{\Delta \beta}=\frac{\mathrm{q}_{\mathrm{i}}-\mathrm{q}_{0}}{\beta-\beta_{0}} & \\
\alpha_{i}=\mathrm{c}_{\alpha 2}\left(\frac{\Delta \mathrm{q}}{\Delta \alpha}\right)^{3}+\mathrm{a}_{\alpha 2}\left(\frac{\Delta \mathrm{q}}{\Delta \alpha}\right)^{2}+\mathrm{m}_{\alpha 2} \frac{\Delta \mathrm{q}}{\Delta \alpha}+\mathrm{b}_{\alpha 2} & \text { For } 25^{\circ}<\alpha<75^{\circ} \\
\alpha_{i}=\mathrm{c}_{\alpha 3}\left(\frac{\Delta \mathrm{q}}{\Delta \alpha}\right)^{3}+\mathrm{a}_{\alpha 3}\left(\frac{\Delta \mathrm{q}}{\Delta \alpha}\right)^{2}+\mathrm{m}_{\alpha 3} \frac{\Delta \mathrm{q}}{\Delta \alpha}+\mathrm{b}_{\alpha 3} & \text { For }-75^{\circ}<\alpha<-25^{\circ} \\
\beta_{\mathrm{i}}=\mathrm{a}_{\beta 2}\left(\frac{\Delta \mathrm{q}}{\Delta \beta}\right)^{2}+\mathrm{m}_{\beta 2} \frac{\Delta \mathrm{q}}{\Delta \beta}+\mathrm{b}_{\beta 2} & \text { For } 20^{\circ}<\beta<45^{\circ} \\
\beta_{\mathrm{i}}=\mathrm{a}_{\beta 3}\left(\frac{\Delta \mathrm{q}}{\Delta \beta}\right)^{2}+\mathrm{m}_{\beta 3} \frac{\Delta \mathrm{q}}{\Delta \beta}+\mathrm{b}_{\beta 3} & \text { For }-45^{\circ}<\beta<-20^{\circ}
\end{array}
$$

Figure 10 shows as the angle of attack approaches zero degrees the plot does indeed approach infinity as expected. There are two cubic regions for angles of attack with a magnitude between $25^{\circ}$ and $75^{\circ}$. Outside of these regions, the angle of attack is no longer independent of velocity.

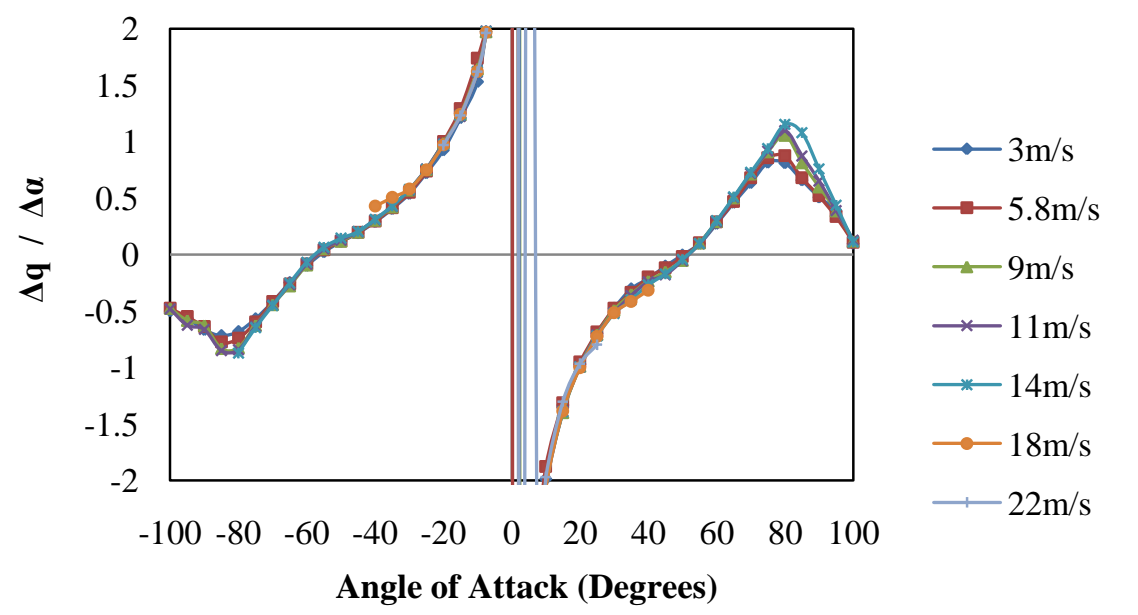

Figure 10: $\Delta \mathrm{q} / \Delta \alpha$ Differential Pressure Voltage Ratio vs. Angle of Attack

Figure 11 shows as the sideslip angle approaches zero degrees cancellation errors occur. Normalization by the differential pressure yields two quadratic curves for sideslip angles with a magnitude between $20^{\circ}$ and $45^{\circ}$. For sideslip angles with a magnitude less than $20^{\circ}$ the sideslip angle is dependent on velocity. 


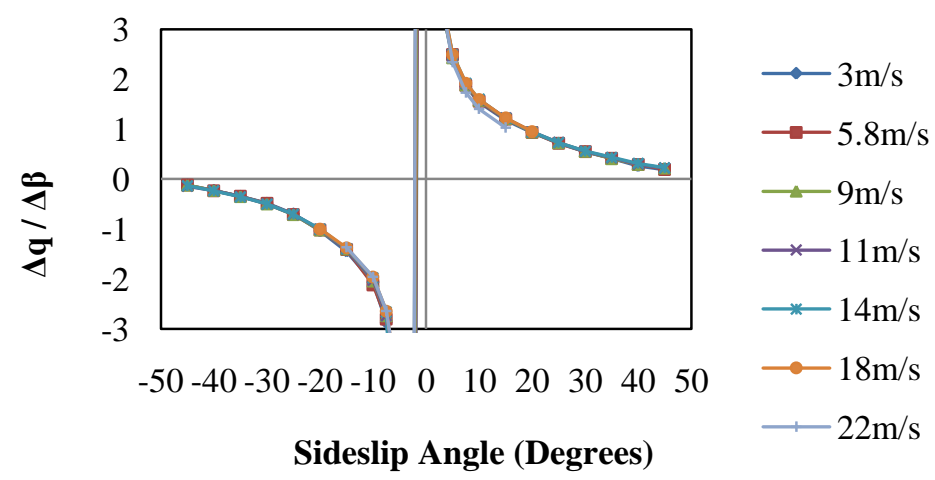

Figure 11: $\Delta \mathrm{q} / \Delta \beta$ Differential Pressure Voltage Ratio vs. Angle of Attack

\section{Calibration Algorithm}

By combining both methods discussed previously, the angle of attack was calibrated for angles between $-75^{\circ}$ and $75^{\circ}$ and sideslip angles between $-45^{\circ}$ and $45^{\circ}$. Figures $12-17$ show the calibration curves, equation of the best-fit curve, and correlation coefficient for angle of attack and sideslip angle.

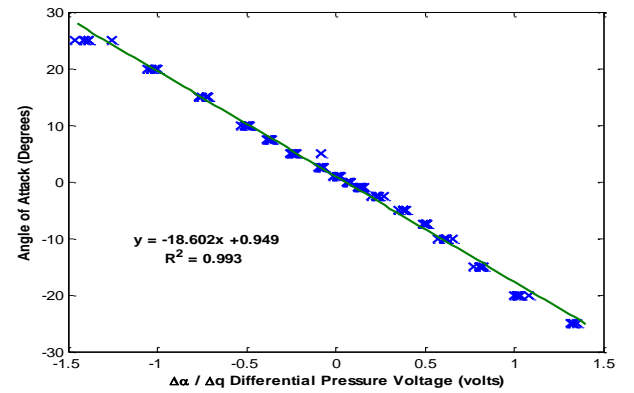

Figure 12: $\alpha$ Calibration Curve $\left(-25^{\circ} \leq \alpha \leq 25^{\circ}\right)$

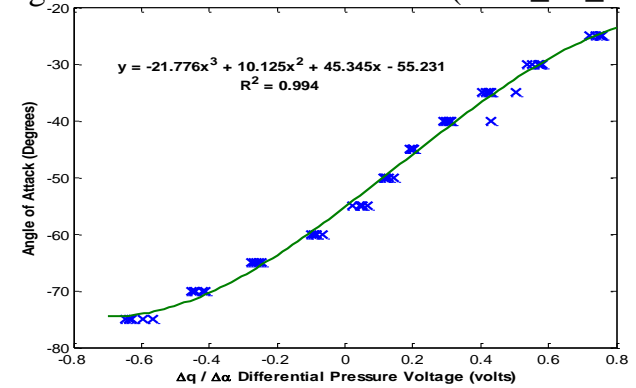

Figure 14: $\alpha$ Calibration Curve $\left(-75^{\circ} \leq \alpha \leq-25^{\circ}\right)$

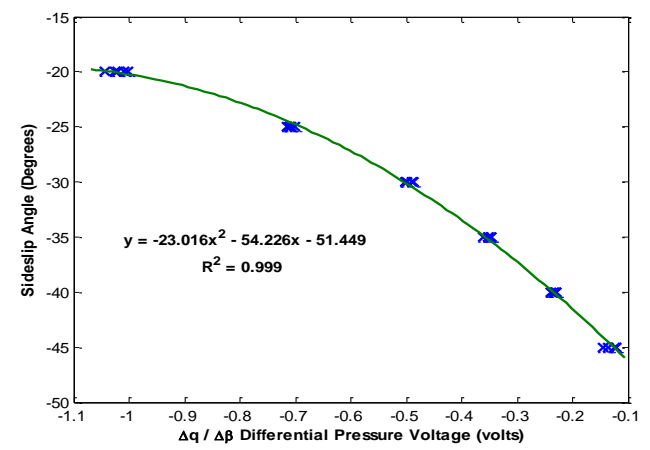

Figure 16: $\beta$ Calibration Curve $\left(-45^{\circ} \leq \beta \leq-20^{\circ}\right)$

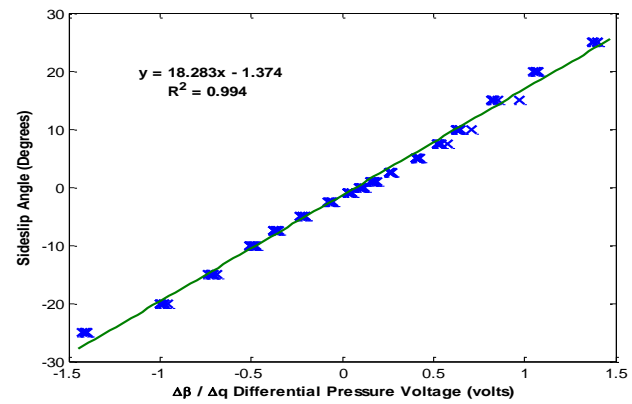

Figure 13: $\beta$ Calibration Curve $\left(-25^{\circ} \leq \beta \leq 25^{\circ}\right)$

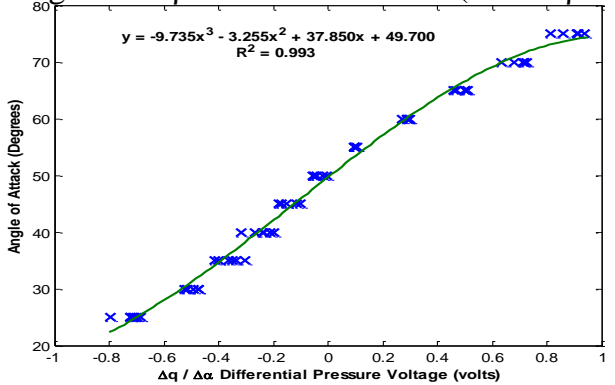

Figure 15: $\alpha$ Calibration Curve $\left(25^{\circ} \leq \alpha \leq 75^{\circ}\right)$

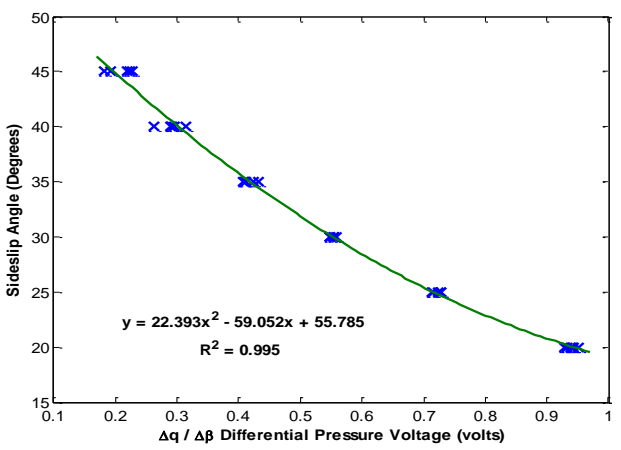

Figure 17: $\beta$ Calibration Curve $\left(20^{\circ} \leq \beta \leq 45^{\circ}\right)$ 
The calibration algorithm uses a median data filter and Eqs. 2-10 to calculate the measured airspeed, angle of attack, and sideslip angle. Each median data filter output receives seven data values as input. The differential pressure ratios are then calculated, and the angle of attack is calculated by first computing the value of Eqs. 2 - 4. The mean of the previous five angles of attack is found to decide, which calibration curve is accurate for the value of angle of attack being calculated.

$$
\begin{aligned}
& \mathrm{V}_{\mathrm{i}}=\mathrm{a}_{\mathrm{q}}\left(\mathrm{q}_{\mathrm{i}}\right)^{2}+\mathrm{m}_{\mathrm{q}}\left(\mathrm{q}_{\mathrm{i}}\right)+\mathrm{b}_{\mathrm{q}} \\
& \Delta \mathrm{q}=\mathrm{q}_{\mathrm{i}}-\mathrm{q}_{0} \quad \Delta \alpha=\alpha_{\mathrm{i}}-\alpha_{0} \quad \Delta \beta=\beta_{\mathrm{i}}-\beta_{0}
\end{aligned}
$$

The final angle of attack calibration is shown below in Eqs. 13 and 14 followed by the sideslip angle calibration in Eq. 15.

$$
\begin{aligned}
& J=\operatorname{mean}\left(\alpha_{\mathrm{i}-5}, \alpha_{\mathrm{i}-4}, \alpha_{\mathrm{i}-3}, \alpha_{\mathrm{i}-2}, \alpha_{\mathrm{i}-1}\right) \\
& \mathrm{K}_{1}=\mathrm{m}_{\alpha 1} \frac{\Delta \alpha}{\Delta \mathrm{q}}+\mathrm{b}_{\alpha 1} \quad \mathrm{~K}_{2}=\mathrm{c}_{\alpha 2}\left(\frac{\Delta \mathrm{q}}{\Delta \alpha}\right)^{3}+\mathrm{a}_{\alpha 2}\left(\frac{\Delta \mathrm{q}}{\Delta \alpha}\right)^{2}+\mathrm{m}_{\alpha 2} \frac{\Delta \mathrm{q}}{\Delta \alpha}+\mathrm{b}_{\alpha 2} \\
& \mathrm{~K}_{3}=\mathrm{c}_{\alpha 3}\left(\frac{\Delta \mathrm{q}}{\Delta \alpha}\right)^{3}+\mathrm{a}_{\alpha 3}\left(\frac{\Delta \mathrm{q}}{\Delta \alpha}\right)^{2}+\mathrm{m}_{\alpha 3} \frac{\Delta \mathrm{q}}{\Delta \alpha}+\mathrm{b}_{\alpha 3}
\end{aligned}
$$

For the current angle of attack to be estimated, the magnitude difference between the calculated value and the last angle of attack value must be less than $30^{\circ}$, and for the outer curves the mean of the previous angles of attack must be greater than $20^{\circ}$. The acceptable range for each curve has been increased for both the minimum and maximum range by $5^{\circ}$ so that there is an overlap region between the outer curves and the middle range curve. The magnitude between calculated and previous value is checked to prevent large jumps between values that would otherwise occur as the airspeed becomes low such as during a hover. The mean of the previous values is used to signal when the switch between the middle curve and the outer curves should occur. If the values from the curves do not fit any of these criteria then a flag is set as the current reading falls outside of our calibration and is likely erroneous. The sideslip angle calculation uses the same logic as the angle of attack the difference being the ranges for the curves.

$$
\alpha_{\mathrm{i}}=\left\{\begin{array}{lr}
\mathrm{K}_{2} & 25^{\circ}<\mathrm{K}_{2}<80^{\circ} \text { and }\left|\alpha_{\mathrm{i}-1}-\mathrm{K}_{2}\right|<30^{\circ} \text { and } \mathrm{J}>20^{\circ} \\
\mathrm{K}_{3} & -80^{\circ}<\mathrm{K}_{3}<-25^{\circ} \text { and }\left|\alpha_{\mathrm{i}-1}-\mathrm{K}_{3}\right|<30^{\circ} \text { and } \mathrm{J}<-20^{\circ} \\
\mathrm{K}_{1} & -30^{\circ}<\mathrm{K}_{1}<30^{\circ} \text { and }\left|\alpha_{\mathrm{i}-1}-\mathrm{K}_{1}\right|<20^{\circ} \\
\text { FLAG } & \text { Otherwise }
\end{array}\right.
$$

$\mathrm{J}=\operatorname{mean}\left(\beta_{\mathrm{i}-5}, \beta_{\mathrm{i}-4}, \beta_{\mathrm{i}-3}, \beta_{\mathrm{i}-2}, \beta_{\mathrm{i}-1}\right)$

$\mathrm{K}_{1}=\mathrm{m}_{\beta 1} \frac{\Delta \beta}{\Delta \mathrm{q}}+\mathrm{b}_{\beta 1} \quad \mathrm{~K}_{2}=\mathrm{a}_{\beta 2}\left(\frac{\Delta \mathrm{q}}{\Delta \beta}\right)^{2}+\mathrm{m}_{\beta 2} \frac{\Delta \mathrm{q}}{\Delta \beta}+\mathrm{b}_{\beta 2} \quad \mathrm{~K}_{3}=\mathrm{a}_{\beta 3}\left(\frac{\Delta \mathrm{q}}{\Delta \beta}\right)^{2}+\mathrm{m}_{\beta 3} \frac{\Delta \mathrm{q}}{\Delta \beta}+\mathrm{b}_{\beta 3}$

$$
\beta_{\mathrm{i}}=\left\{\begin{array}{lr}
\mathrm{K}_{2} & 20^{\circ}<\mathrm{K}_{2}<50^{\circ} \text { and }\left|\beta_{\mathrm{i}-1}-\mathrm{K}_{2}\right|<30^{\circ} \text { and } J>20^{\circ} \\
\mathrm{K}_{3} & -50^{\circ}<\mathrm{K}_{3}<-20^{\circ} \text { and }\left|\beta_{\mathrm{i}-1}-\mathrm{K}_{3}\right|<30^{\circ} \text { and } \mathrm{J}<-20^{\circ} \\
\mathrm{K}_{1} & -30^{\circ}<\mathrm{K}_{1}<30^{\circ} \text { and }\left|\beta_{\mathrm{i}-1}-\mathrm{K}_{1}\right|<20^{\circ} \\
\text { FLAG } & \text { Otherwise }
\end{array}\right.
$$

\section{E. Calibration Algorithm Validation}

Calibration algorithm validation was achieved using wind tunnel test data. The data used for the calibration was put through the algorithm for each separate velocity to ensure that our calibration curves are indeed independent of 
velocity and fit closely to the measured flow angle. Figure 18 shows a plot of the calculated flow for a sweep of angles between $-75^{\circ}$ and 75 in five degree increments. The data points shown are what the calibration curves should ideally calculate as the measured flow angle. As can be seen the algorithm fits quite well to the actual flow angle except in the range $45^{\circ}$ to $65^{\circ}$ where the curve fit is not ideal. Combining the data for all velocities and calculating the magnitude of the error between the calculated and actual flow angles the mean value of the error is $0.95^{\circ}$ with a standard deviation of $0.70^{\circ}$ and the mean plus four standard deviations is $3.8^{\circ}$. Therefore, the maximum error on our data is reasonably low considering the high angles of attack being measured.

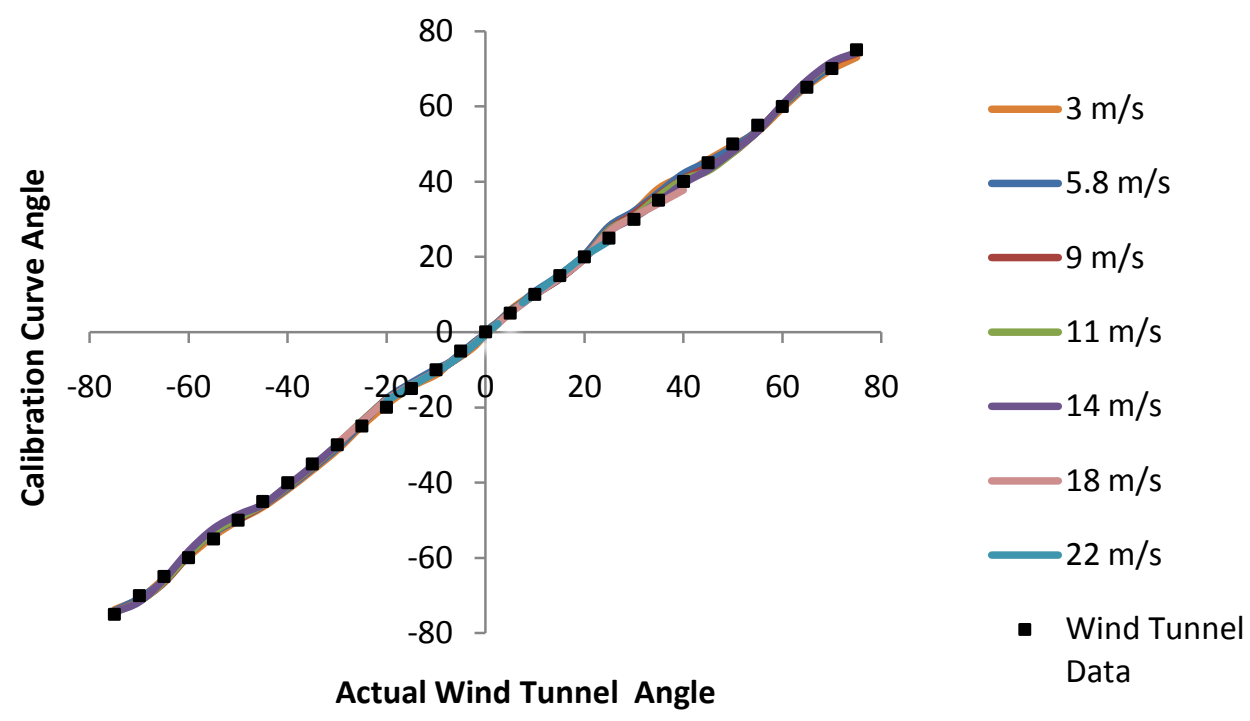

Figure 18: Calibration Algorithm Angle vs. Measured Wind Tunnel Flow Angle

Figure 19 shows a plot of the calculated angle of attack from the calibration algorithm as the angle of attack is varied from $0^{\circ}$ to $80^{\circ}$ to $-80^{\circ}$ in increments of $5^{\circ}$ during wind tunnel testing. As shown, the curve fit switches accurately between the regions of validity. Note that the $\mathrm{x}$-axis represents data set number, not time, as data was collected statically and angle of attack was altered manually in the wind tunnel.

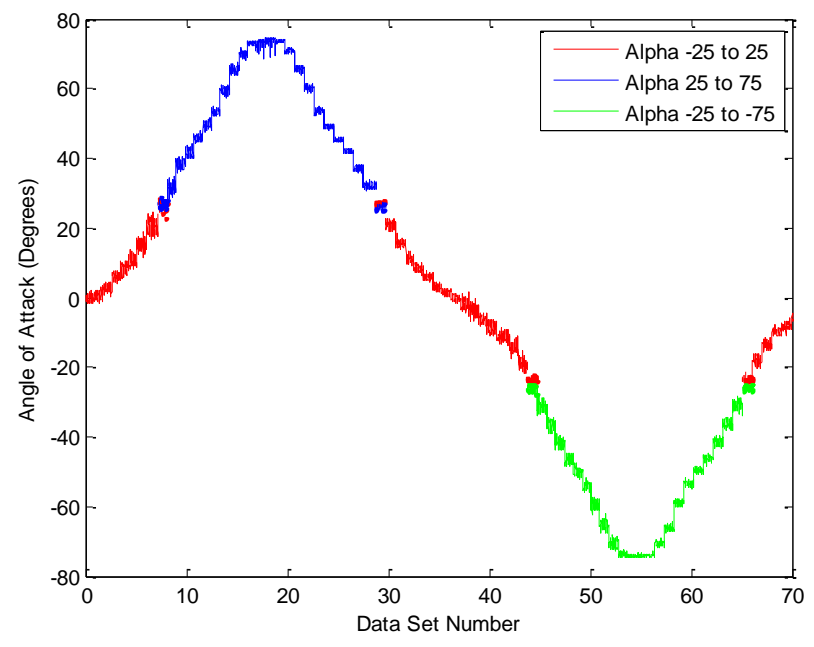

Figure 19: Angle of Attack Varied in 5 degree Increments in an Interval [-80 80] Degrees

\section{F. Real-time Pressure Based Stall Detection}

The addition of wing pressure sensors allows for the detection of a deep wing stall or when boundary layer separation has occurred across the top of the wing thereby severely reducing lift generation.. Such a detection capability plays an important role in our proposed transition strategy presented in Section VI by enabling autopilot mode switching and actuator regulation based on vehicle aerodynamic as well as inertial state. 
Our stall detection algorithm operates on the principle that if the static pressure measurements along the top of the wing converge to similar, low values, then the main flow has separated from the top of the airfoil leaving pockets of re-circulating air above the wing. This traditional notion of stall is readily observed with wind tunnel experiments. The following coefficient of pressure (Cp) data was taken in the 2'x2' UM wind tunnel over a generic NACA 2412 airfoil flying at a Reynolds number of 110,000. Figure 20 shows this 'loss of suction' trend over the top of the airfoil after stall. This type of behavior is typical for airfoils operating under similar Reynolds numbers.
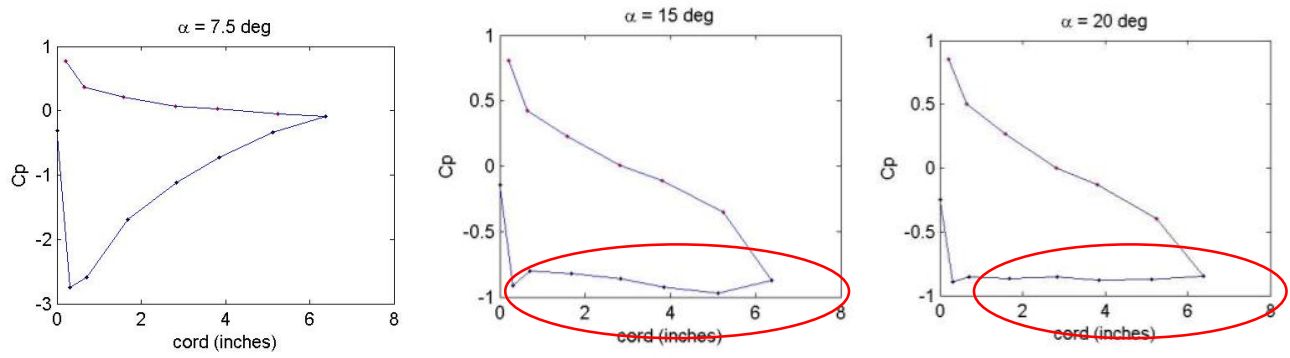

Figure 20: Cp Trends from Wind Tunnel Test Data

These wind tunnel test results extrapolate to flight conditions across the Funtana's $30 \mathrm{~cm}$ test section at airspeeds of $\sim 5 \mathrm{~m} / \mathrm{s}$ as encountered during a transition from forward flight (left panel of Figure 20) to and including stall (center and right panels of Figure 20). . The Funtana, as previously discussed, is equipped with a stagnation port and four pressure ports along the top chord of the wing, providing a means to approximate the pressure profile. To characterize wing lift properties, wing pressure port sensor readings are first normalized by the measured dynamic pressure to construct a $\mathrm{Cp}$ profile. To indicate a sufficient airspeed, the profile must show that the pressure distribution along the top of the wing chord is small with respect to dynamic pressure. Additionally, the $\mathrm{Cp}$ variation between the different wing ports must be small to indicate stall as illustrated in Fig. 20. During a transition to hover, the dynamic pressure experienced by the aircraft becomes small due to the very low airspeeds, introducing $\mathrm{Cp}$ calculation problems during the normalization process.

To overcome these problems at very low speeds, the stall detector is coupled with a "Loss-of-Lift" detector that considers pressure readings not normalized by the dynamic pressure. Once the actual pressure difference between the stagnation point of the wing and its top surface becomes negligible, the wing is no longer be an aerodynamic lifting surface. Since mild wing stall can occur without a total loss of wing lift, using both detection algorithms allows the aerodynamic data system to estimate the severity of a stall during flight.

$$
\begin{gathered}
\text { Profile }=\left[\mathrm{P}_{1}, \mathrm{P}_{2}, \mathrm{P}_{3}, \mathrm{P}_{4}, \ldots \mathrm{P}_{\mathrm{n}}\right] \\
\mathrm{Cp}_{\text {min }}=\min _{\mathrm{i}=1 . \mathrm{n}}\left(\frac{\mathrm{P}_{\mathrm{i}}}{\mathrm{q}}\right) \quad \mathrm{Cp}_{\text {diffs }}=\sum_{i=1}^{\mathrm{n}-1} \frac{\left|\mathrm{P}_{\mathrm{i}+1}-\mathrm{P}_{\mathrm{i}}\right|}{\mathrm{q}} \quad \mathrm{P}_{\text {diffs }}=\sum_{i=1}^{\mathrm{n}-1}\left|\mathrm{P}_{\mathrm{i}+1}-\mathrm{P}_{\mathrm{i}}\right| \\
\text { Stall State }=\left\{\begin{array}{cc}
\text { Total Lift Loss } & \mathrm{q}<\mathrm{q}_{\text {thresh }} \text { and } \mathrm{P}_{\text {diffs }}<\mathrm{P}_{\text {diffs min }} \\
\text { Stall } & \mathrm{Cp}_{\text {min }}>-1 \text { and } C p_{\text {diffs }}<0.4 \\
\text { No Stall Detected } & \text { Otherwise }
\end{array}\right.
\end{gathered}
$$

During flight tests, a combination of both the Cp-based stall detector and the pressure difference-based loss-of-lift detector was successful in indicating conditions during a transition when the aircraft entered a stall condition and when wing lift became no longer available, as described below.

\section{Flight test results.}

The Funtana was remotely flown both in level flight and vertical hover to collect pressure and inertial data during steady flight and transitions between forward flight and hover modes, over multiple flight test days. The pilot executed transitions on a straight and level flight path into the prevailing wind over a distance of approximately 15 meters indicated by the GPS data. The pilot held the aircraft in a hover using the ground as a reference frame before 
transitioning back into the forward flight mode. The system was also flown at level flight through a series of race track patterns. Figure 21 shows the reported IMU roll angle, wing pressure port readings in inches of water and the variation between inertial pitch and measured angle of attack in a turn and followed by straight and level flight.

\section{A. Forward Flight Results}

The aerodynamic data system was initially verified in flight during steady cruise conditions. Results from one flight are shown in Figure 21. Angle of attack and sideslip measurements corresponded well with inertial data. Wing pressure measurements verified that the chosen sensor configuration was suitable for the range of pressure differences encountered. Considering airspeed measurements taken from steady cruise flight data, the free stream turbulent intensity was found to be between $0.3 \%-1.0 \%$ under cruise conditions. This is expected for flows originating from a mainly stationary fluid.
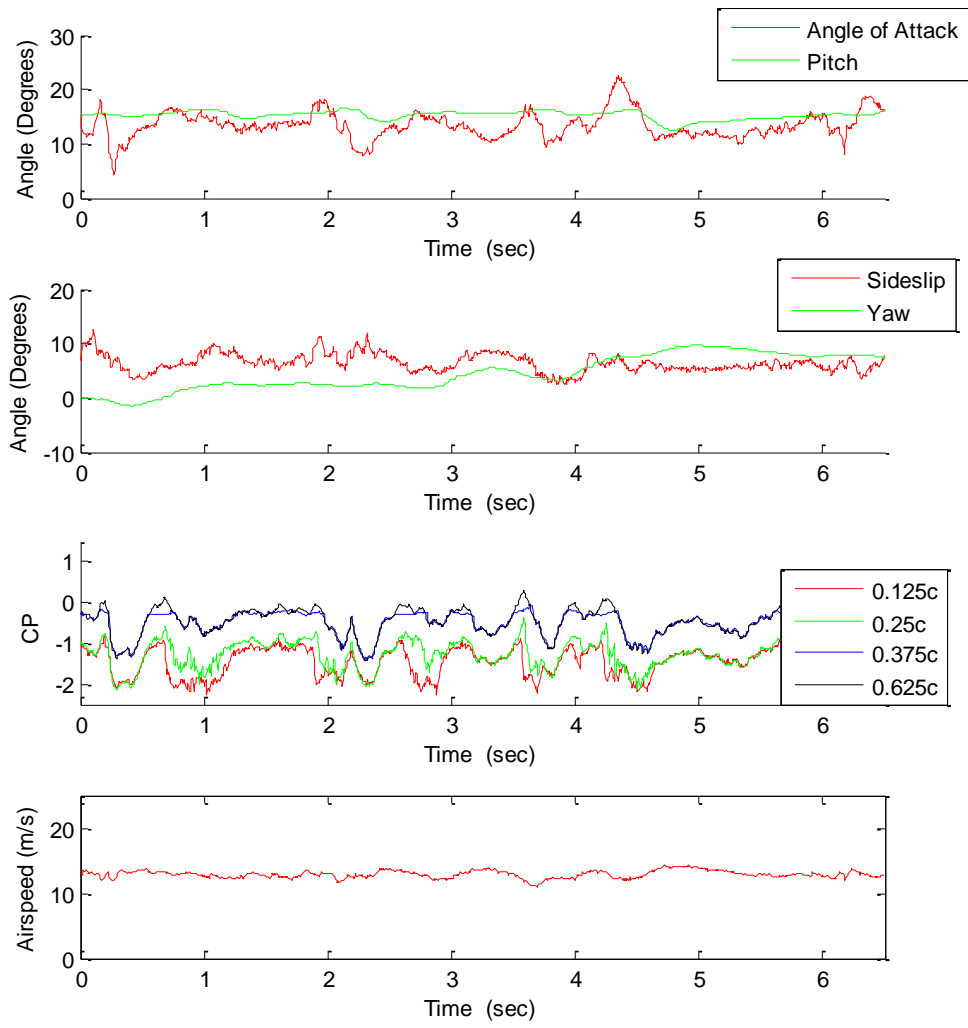

Figure 21: Aerodynamic Data during Forward Flight

\section{B. Hover Transition Results}

Figure 22-23 show a time history of measured INS pitch angle, angle of attack, airspeed, and wing chord pressure sensor data as the Funtana is manually transitioned from forward flight into a near vertical attitude, and hovered. The collected angle of attack data corresponds well with expected values and with other flight data. Also shown is that the aerodynamic data is sufficiently accurate to be used during a transition to hover and within our guidance/control strategy over the course of a transition. Presented with Figure 22 is a comparison of both stall and loss-of-lift indicators throughout a transition. The results show stall occurring during the earlier part of the transition and progressing to a total loss of wing lift as airspeed decreases further.

In Figure 22 the angle of attack and pitch angle have a clear relationship . As pitch angle increases the airspeed shown in Figure 22 decreases keeping the angle of attack close in magnitude to the pitch angle. However, once the airspeed decreases below approximately $2.5 \mathrm{~m} / \mathrm{s}$ at about 7.5 seconds the algorithm returns erroneous values for the angle of attack. These erroneous values are expected because there is little pressure difference between any of the tubes when there is little airflow. Once the airspeed increases above $2.5 \mathrm{~m} / \mathrm{sec}$ at a time of $\sim 11$ seconds the algorithm again returns reasonable values. 

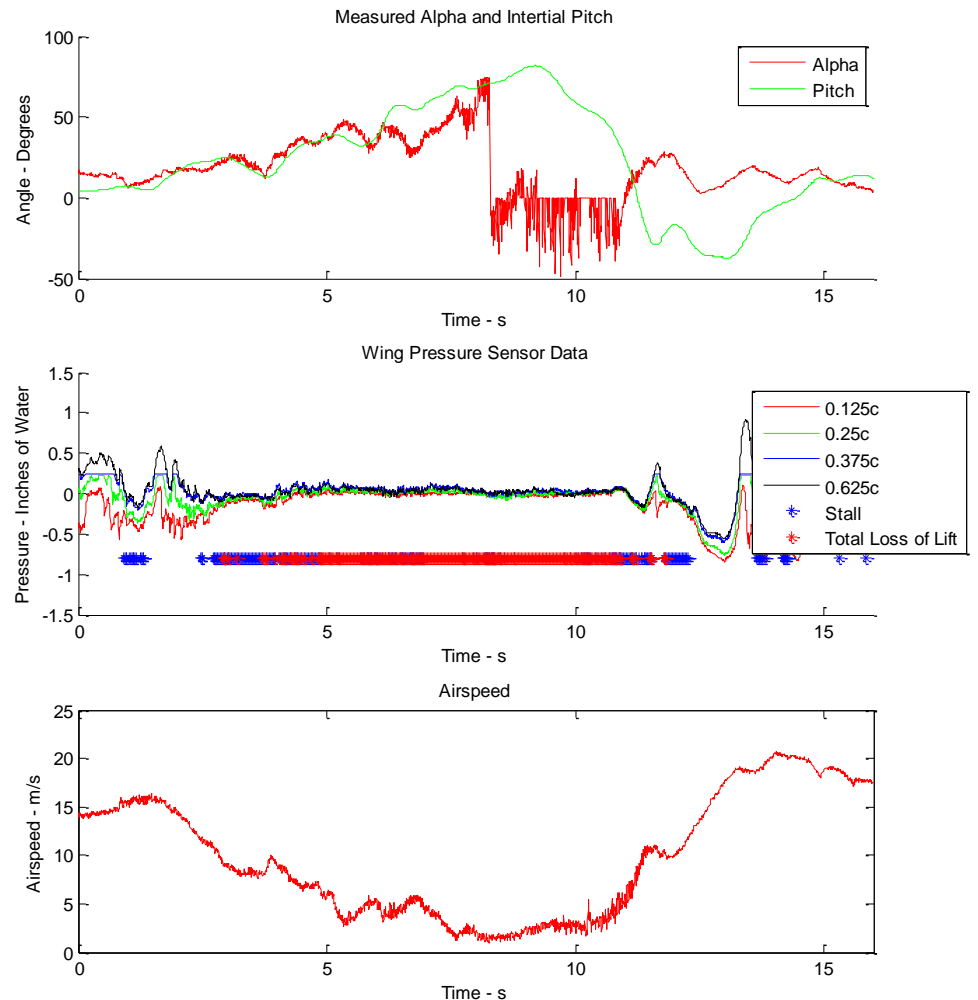

Figure 22: Hover Transition Data for Pitch, Angle of Attack, and Pressure Port Readings

Figures 22 and 23 show that in a hover state pressure readings on the wing's chord drop to near zero. At this point it can be argued that the wings begin to function similar to control vanes directing propeller wash rather than as lifting surfaces. A lift-based controller will thus be ineffective requiring switch to a hover controller. Figure 22 shows pressure data after reaching a hover state. Figure 23 shows the full sequence of representative readings for a pressure port: transition to hover, hover, and exit from hover.

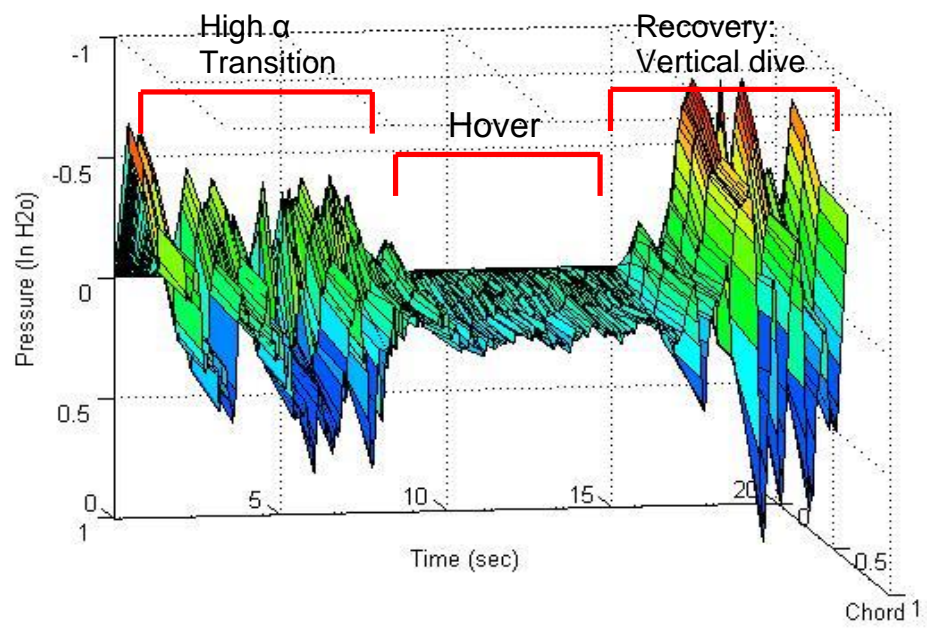

Figure 23: Flight Maneuver Sequence including Transition, Hover, and an Exit Dive 


\section{Transition Guidance}

Our guidance strategy takes advantage of aerodynamic state information to trigger discrete autopilot mode changes. Autopilot design choices are supported from manually-piloted flight transition experiences. During a transition, the aircraft is flown at a low power setting until a total loss of lift condition is reached. The throttle is then raised and the elevator command is given to pitch the aircraft to vertical. Figure 24 shows example elevator and throttle commands during a forward flight to hover transition.
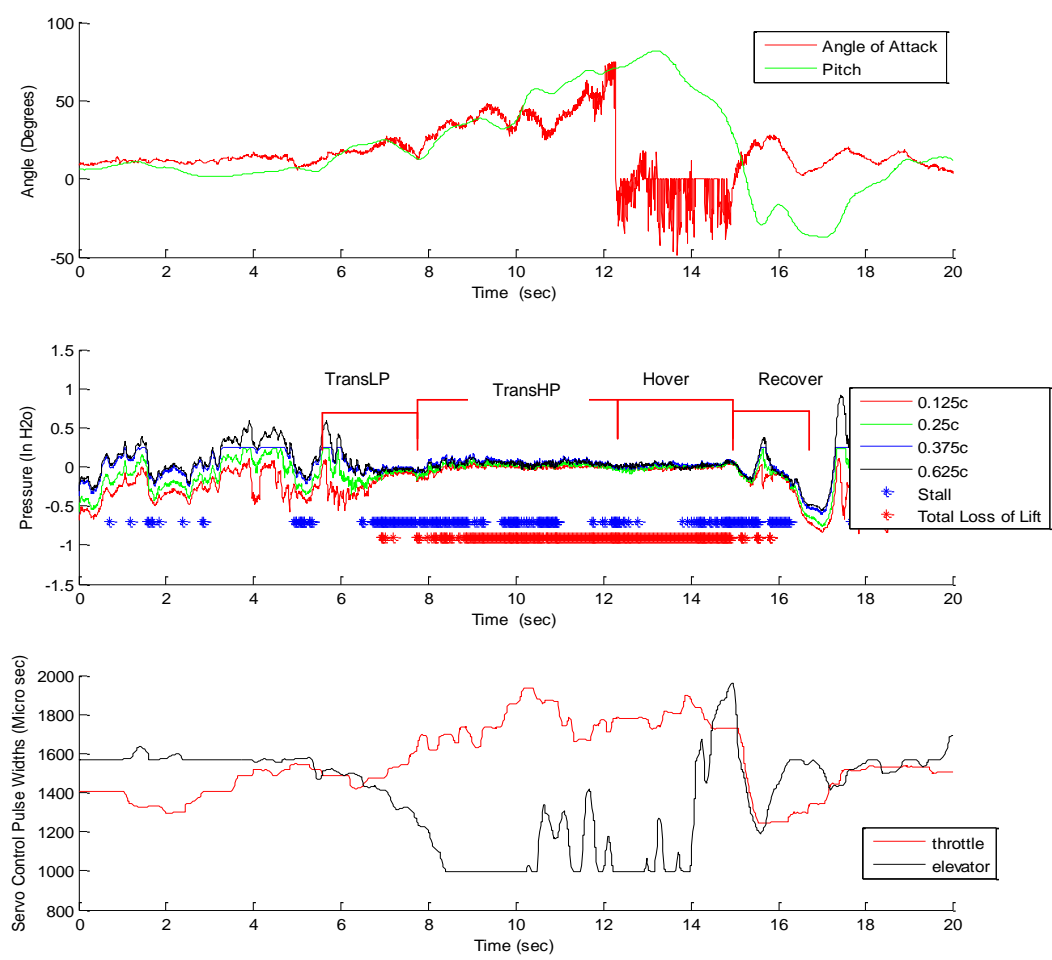

Figure 24: Hover Transition Flight Data

(Top: Angle of Attack and Pitch, Middle: Wing Chord Pressure Distribution, Bottom: Pilot Servo Commands)

It has been seen that pilot estimations of a deep stall condition tend to be premature. With the improved observations of stall/loss of wing lift afforded by the aerodynamic data system, we hypothesize that a stall-based guidance strategy can improve on human piloted transitions. We therefore describe transition guidance with five discrete autopilot states: Cruise, Transition Low-Power (TransLP), Transition High-Power (TransHP), Hover, and [Hover] Exit. Figure 25 illustrates our mode-based guidance strategy. Cruise mode autonomously flies the aircraft at steady level conditions until a transition is commanded, currently by the pilot via $\mathrm{R} / \mathrm{C}$ transmitter. Once initiated, TransLP decelerates the aircraft at a low throttle setting and begins to pitch the nose to a higher angle of attack while maintaining a constant altitude up to the point when the aircraft wing enters a stall condition. If the aircraft fails to achieve a moderate, positive pitch angle by this time, the autopilot that the aircraft is unable to complete a full transition and aborts the maneuver. Otherwise, the autopilot continues the low-throttle pull-up in TransLP. Once a total Loss of Lift condition is detected, TransHP is initiated and begins to increase the throttle setting in order to balance weight with thrust. At the same time, elevator commands are given to raise the pitch angle of the aircraft and complete the transition to a hover mode. In hover, the airspeed and wing pressure data system afford additional inputs that allow the autopilot to detect situations when the aircraft begins to develop airspeed while oriented vertically. Airspeed is used to set a "Brake" condition that commands throttle reduction if appreciable vertical airspeed is detected. After a predetermined period of time, hover mode is disengaged and the recovery autopilot pitches the aircraft downwards until it detects recovery from a Loss of Lift condition to a stall condition, indicating that the wing is beginning to experience some forward airflow. It then holds this pitch angle until recovery to a normal, forward flight condition is re-established. 


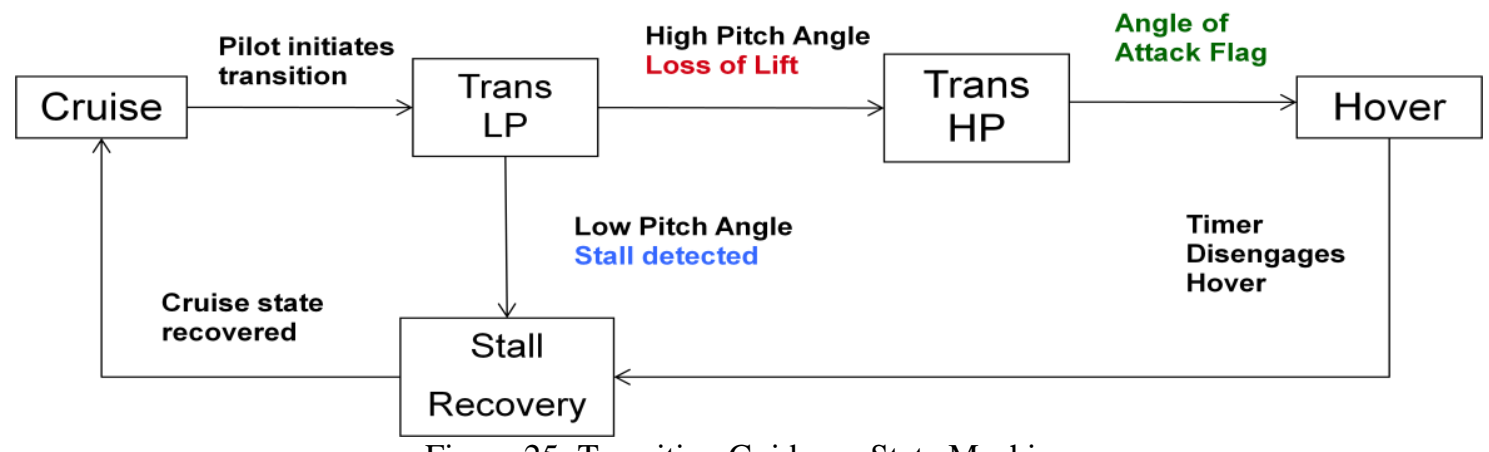

Figure 25: Transition Guidance State Machine

During flight testing, the aircraft is manually configured for an approach at the far end of the flying field. The autopilot is then given control to perform its transition sequence. Once the aircraft is sufficiently far downwind in cruise, manual control is regained and the aircraft is repositioned for another pass.

\section{Flight Test Plan and Progress To-Date}

Our proposed guidance strategy was implemented and flight tested on the Funtana platform. Objectives included showing our control system was capable of flying transitions with little altitude variation, as well as validating the ability to robustly transition between guidance modes based on stall and loss-of-lift detection. Decoupled linear longitudinal and lateral controllers are used to regulate the different autopilot modes and have been sufficient during tests to-date. Gains were scaled over a large range of airspeed from cruise to near zero for Trans LP. The sequence of flight tests is shown below. To-date goals 1a through 4a have been accomplished. Figures 26 to 28 show the effectiveness of the current autopilot during test flights.

1-Piloted flights:

a- Data logging

b- Offline verification of aerodynamic data system

c- Offline estimation of controller parameters

2-Cruise mode autopilot

a- Tune decoupled roll and yaw controllers - pilot assisted

b- Tune decoupled pitch and altitude controllers - pilot assisted

c- Verify switch conditions - autonomous

3-Trans LP autopilot

a- Tune roll and yaw controllers for wide airspeed range to stall -pilot assisted

b- Tune pitch and altitude controllers for wide airspeed range to stall -pilot assisted

c- Maintain level attitude to stall and lift loss condition - autonomous, manual recovery

d- Verification of stall/loss of lift switch conditions - autonomous, manual recovery

4-Trans HP / Hover autopilot

a- Tune roll and yaw controllers for low speed, high angle of attack flight -pilot assisted

b- Tune pitch and altitude hold controllers for high power transition phase - autonomous

c- Test airspeed based switch and 'brake' conditions - autonomous 

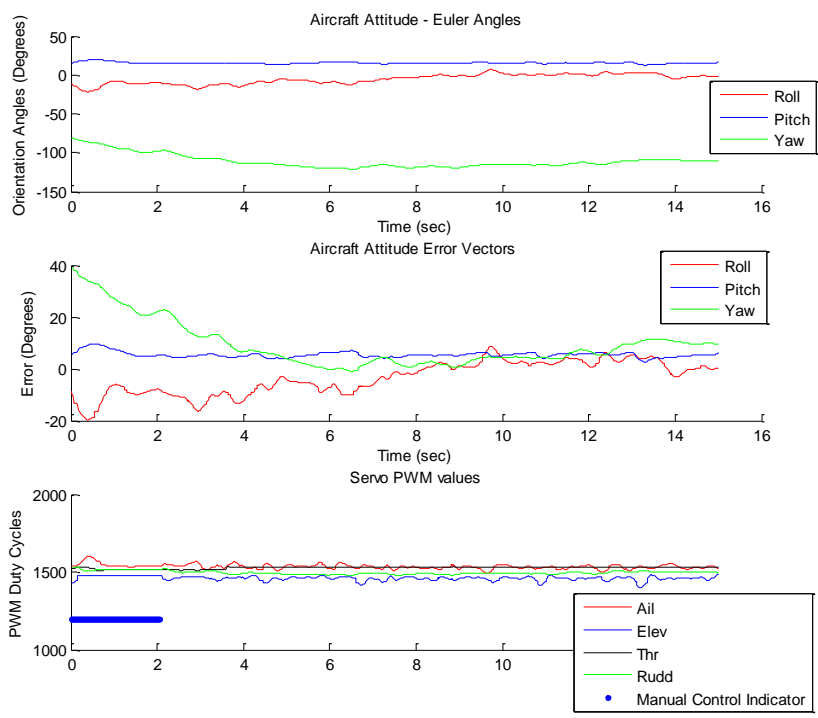

Figure 26: Cruise Autopilot Maintaining Level Flight
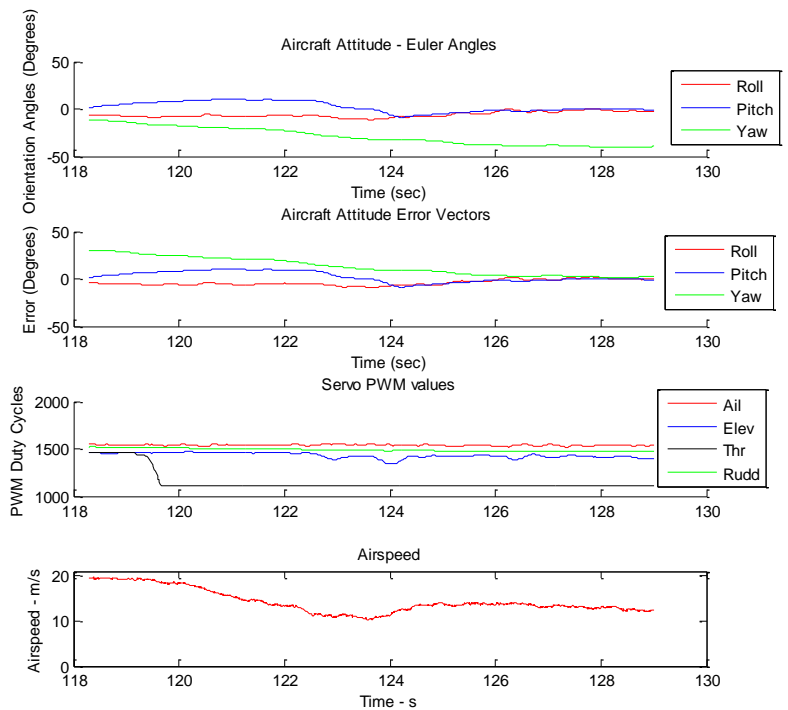

Figure 27: TransLP Autopilot Maintaining Stability with Airspeed Loss

\section{Conclusions and Future Work}

We have presented the design, implementation, calibration, and flight testing of an aerodynamic data system embedded within an aerobatic R/C airframe. Wind tunnel and flight test results indicate the system is capable of providing estimates of wind vector speed and direction and flow over the wing through a wide range of angles of attack, sideslip, and wind speeds. The test results show this additional aerodynamic data can be used as feedback during high angle of attack transitions to/from hover. A transition guidance strategy has been presented that utilizes the additional aerodynamic feedback for autopilot mode switching. Flight tests to tune and validate the fullyautomated sequence are in progress, with early results promising.

Near term, we plan to complete our ongoing set of flight tests to validate our mode switching and feedback control strategies. Beyond that, we hope to expand the suite of pressure ports to better measure flow induced by the propeller over the wing root and tail particularly during hover. We hypothesize that incorporation of these measurements will further improve slow, high angle of attack flight as well as performance of our hover controller. 

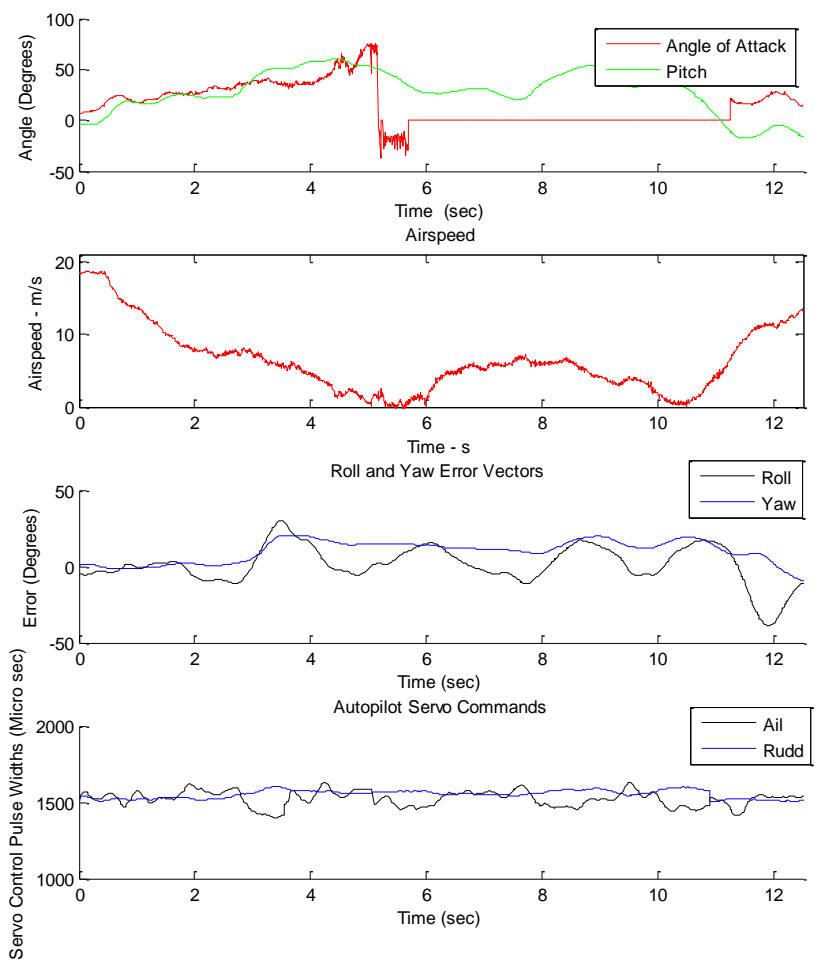

Figure 28: Autopilot Assisting Pilot in Roll and Yaw during Transition and Hover

\section{Acknowledgments}

We would like to thank Master Sergeant Balwinski and the dedicated personnel of the Michigan Army National Guard at Camp Grayling who enabled us to conduct our test flights. We would also like to acknowledge Ayden Zhiwei Song for his contributions to the Alpha-Beta probe.

\section{References}

1 Frank, A., Valenti, M., Levine, D., and How, J. P., "Hover, Transition, and Level Flight Control Design for a Single-Propeller Indoor Airplane", Proceedings of the AIAA Guidance, Navigation, and Control Conference and Exhibit, Hilton Head, SC, August 2007

2 Johnson, E., Wu, Neidhoefer, J., Kanna and Turbe. "Flight-Test Results of Autonomous Airplane Transitions Between Steady-Level and Hovering Flight," AIAA Journal of Guidance, Control, and Dynamics, Vol. 31, No. 2, March-April 2008.

3 Beard, R., Kingston, ,D., Quigley, M., Snyder, D., Christiansen, R., Johnson, W., McLain, T. and Goodrich, M. "Autonomous Vehicle Technologies for Small Fixed Wing UAVs," AIAA Journal of Aerospace Computing, Information, and Communication, Vol. 2, January 2005

4 Johnson, B., and Lind, R., "High Angle-of-Attack Flight Dynamics of small UAVs," 47th AIAA Aerospace Sciences Meeting Including The New Horizons Forum and Aerospace Exposition, 5 - 8 January 2009, Orlando, Florida (AIAA 2009-61).

5 Anderson, J. D., Fundamentals of Aerodynamics, $4^{\text {th }}$ ed. , McGraw Hill Series in Aeronautical and Aerospace Engineering, 2005.

6 Ostowari, C., Wentz, W. H., "Modified Calibration Technique of a Five-Hole Probe for High Flow Angles," Experiments in Fluids, Vol. 1, No. 3, Sept. 1983, pp. 166-168.

7 Tropea,C., Yarin,A., Foss,J., Springer handbook of experimental fluid mechanic, Springer; First edition, December 20, 2007 pp. 215-225. 